rejected as too costly. But the Northumberland Committee's estimates of the likely cost of prophylactic vaccination- $£ 13$ million in the first year and $£ 5$ million annually thereafter-should put an end to the ridiculously high estimates that have been bandied about by antivaccination lobbies. And the Government's acceptance of the recommendation that contingency plans for ring vaccination in the event of an outbreak should be prepared, even though they will cost about $f 1$ million a year, is the most encouraging outcome of the inquiry. This means that vaccination is no longer automatically equated with accepting the disease as endemic.

Unfortunately, however, the committee did not recommend that ring vaccination should be used immediately an outbreak occurs but was content to say that "ring vaccination would not limit the number of primary outbreaks but it could limit spread. Although it has considerable disadvantages, we think that in certain conditions ring vaccination could be a useful adjunct to slaughter". Who will decide when an outbreak has reached a great enough size to warrant vaccination? And how great must the outbreak be before vaccination is started? Only one memberMr A. Cripps, QC - of the committee of eight, in a dissenting note, said that "the immediate application of ring vaccination to any outbreak which occurs seems to me essential". 'The obvious advantage of this policy, apart from reducing immediately the risks of the disease spreading, is that it leaves no room for interminable argument and lobbying about when an outbreak has reached a size which warrants vaccination.

\section{NUCLEAR POWER}

\section{The Tobacco Renctor}

THE United Kingdom Atomic Energy Authority is all set to sell its first nuclear power station abroad for ten years. As part of an intricate trading agreement, the AEA hopes to supply the Public Power Corporation of Greece with a steam generating heavy water plant, and in return the Greek Government is hoping to sell quantities of Greek tobacco in Britain. The irony of replacing Rhodesian tobacco with imports from Greece cannot have escaped even the most unpolitical of the salesmen at the AEA, but this does not mean that the authority has not done well in getting as far as it has done.

The negotiations involve the AEA and the Greek Public Power Corporation on the reactor side and United City Merchants and the Greek Tobacco Board on the tobacco deal. If things go well, the AEA will build a 450 megawatt $S G H W$ reactor at a site about thirty miles from Athens. This would be the first SGHW to be exported from the United Kingdom, the earlier attempt to sell one to Finland having collapsed when the Finnish authorities decided to steer clear of nuclear generation for the time being. The only SGHW operating in Britain at present is the one at Winfrith in Dorset, which is supplying the national grid with about $100 \mathrm{MW}$ of power.

It is the flexibility of the SGHW system that seems to have caught the eye of the Greek power authority. For one thing, the reactor can use a variety of possible fuels, of which the cheapest and most probable is the enriched uranium used at Winfrith. The SGHW is also considered to have high intrinsic safety, and the flexibility of its operating conditions makes it a very attractive proposition for the medium sized power demand envisaged by the Greek Power Corporation.

A further advantage of an SGHW station is that much of the constructional work can take place in the factory rather than on the building site. It is expected that about 70 per cent of the cost of the Greek power station will go towards paying for prefabricated parts manufactured in Britain. With the total cost of the power station expected to exceed $£ 30$ million, this represents a sizable export figure. The plant should be completed and up to full power by 1974 .

British companies have not exported a nuclear power station since the first success a decade ago, when they sold two of the first generation of gas cooled graphite moderated power plants, one to Italy and one to Japan. Since then Japan has bought information on the SGHW from the AEA and a new attempt to sell the latest model of advanced gas cooled reactor is now under way, to South Korea (see page 515).

Political factors necessarily play a part in both the Greek and Korean reactor deals. In the first, the Board. of Trade describes the present state of trade between Britain and Greece as "normal", subject only to Britain not furnishing goods that could be used for internal suppression. But much may depend on the relationship between Greece and other members of the Council for Europe in the days ahead.

\section{TECHNICAL RESEARCH

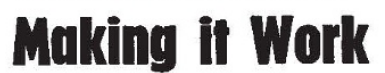

\section{from a Correspondent}

ON May 5 the Institute of Physics and the Physical Society held a conference in London on the organization and management of research and development. Mr P. Trier, director of the Mullard Research Laboratory, set out to distinguish between research and development and their proper modes of organization. He decried the conventional basic/applied dichotomy: alf industrial research and development is applied, but a. distinction is to be made between radical innovation, which is the practice of research, and the later stages of design and production engineering-developmentwhich is intimately tied to economic considerations. Mr Trier favoured separate development laboratories attached to individual project decisions: this aids the symbiosis between design and manufacture, needed to ensure commercial success. This opinion, however, was contested later; views on this aspect of organization seem to vary widely.

Economic features of development were analysed further by an accountant, Mr J. Bullock (Robson, Morrow and Co.), who emphasized the vital importance of maintaining month by month estimates of costs (including forward commitments) attributable to the development project, so that an up to date comparison with forecast expenditure could frequently be made, preferably with the use of discounted cash flow calculations. This harmonized with Mr Trier's insistence that the viability of development projects needed to be reassessed at regular intervals. Mr Bullock's presentation made elegant use of visual aids, and he delighted the audience with his faintly cynical quotations concerning the justification of research and develop- 